\title{
RELIGIÃO, MATERNIDADE E VIOLÊNCIA: O CASO DE MULHERES DIANTE DE SEUS FILHOS, VÍTIMAS DE MORTES VIOLENTAS
}

\author{
Carolina Teles Lemos* \\ Pedro Antônio Chagas Cáceres ${ }^{* *}$
}

\section{RESUMO}

Referindo-se às relações estabelecidas entre religião, maternidade e violência, este artigo tem por objetivo contribuir com a reflexão sobre essas relações, em contextos de mortes violentas, quando mães enfrentam a perda de um/a filho/a. Trata-se do recorte de uma investigação mais ampla, realizada em 2018, em Goiânia, Goiás, sobre mortes violentas. A pesquisa aconteceu por meio de entrevistas semiestruturadas realizadas com 25 familiares de pessoas vítimas de mortes violentas no Instituto Médico Legal de Aparecida de Goiânia, cidade metropolitana de Goiânia, Goiás, no momento em que estes vinham reconhecer os corpos. A investigação aponta que as mulheres, ao enfrentarem essas situações, muitas vezes recorrem aos mesmos significados religiosos conferidos tradicionalmente à maternidade. Palavras-chave: religião, gênero, maternidade, violência.

\section{RELIGION, MOTHERHOOD AND VIOLENCE: THE CASE OF WOMEN IN FRONT OF THEIR CHILDREN, VICTIMS OF VIOLENT DEATHS}

\footnotetext{
ABSTRACT

Referring to the relations established between religion, motherhood and violence, this article aims to contribute to the reflection on these

* Doutora em Ciências Sociais e da Religião (1998) pela Universidade Metodista de São Paulo (UMESP). Mestra em Ciências da Religião (1994) pela UMESP. Graduação em Pedagogia (1989) e Psicologia (2017). Atualmente é professora titular no Programa de Pós-Graduação Stricto Sensu em Ciências da Religião da Pontifícia Universidade Católica de Goiás.

** Doutor em Ciências da Religião, pela PUC Goiás. Professor no Programa de Pós-Graduação em Ciências da Religião - PUC Goiás.
} 
relationships, in contexts of violent deaths, when mothers face the loss of a child. This is the part of a broader investigation, carried out in 2018, in Goiânia, Goiás, on violent deaths. The research took place through semi-structured interviews, conducted with 25 relatives of people victims of violent deaths, at the Legal Medical Institute of Aparecida de Goiânia, metropolitan city of Goiânia, Goiás, at the time they came to recognize the bodies. The investigation points out that women, when facing these situations, often resort to the same religious meanings traditionally conferred on motherhood.

Keywords: religion, gender, motherhood, violence.

\section{RELIGIÓN, MATERNIDAD Y VIOLENCIA: EL CASO DE LAS MUJERES DELANTE DE SUS HIJOS, VÍCTIMAS DE MUERTES VIOLENTAS}

\section{RESUMEN}

Refiriéndose a las relaciones establecidas entre religión, maternidad y violencia, este artículo tiene como objetivo contribuir a la reflexión sobre estas relaciones, en contextos de muertes violentas, cuando las madres se enfrentan a la pérdida de un hijo. Esta es la parte de una investigación más amplia, llevada a cabo en 2018, en Goiânia, Goiás, sobre muertes violentas. La investigación se llevó a cabo a través de entrevistas semiestructuradas, realizadas con 25 familiares de personas víctimas de muertes violentas, en el Instituto Médico Legal de Aparecida de Goiânia, ciudad metropolitana de Goiânia, Goiás, en el momento en que llegaron a reconocer los cuerpos. La investigación señala que las mujeres, cuando se enfrentan a estas situaciones, a menudo recurren a los mismos significados religiosos tradicionalmente conferidos a la maternidad.

Palabras clave: religión, género, maternidad, violencia.

\section{INTRODUÇÃO}

A religião, ao longo da história, desempenhou importante papel na construção e manutenção de uma concepção idealizada de maternidade, na qual a mulher, enquanto sujeito social, é suprimida e a sua função de mãe é sacralizada. Por outro lado, grande parte das mulheres-mães criam seus filhos em situações muito precárias do ponto de vista econômico, social e cultural, gerando nelas um sentimento paradoxal: por um lado, desejam responder à expectativa gerada em torno de uma maternidade idealizada, por outro lado, percebem a impossibilidade 
de que isso ocorra e veem seus filhos crescendo e desenvolvendo um perfil não desejado por elas. A maternidade nesse contexto vulnerabiliza as mulheres que, em situações de violência, perdem seus filhos. As mulheres que se veem às voltas com o enfrentamento dessas situações muitas vezes recorrem aos mesmos significados religiosos conferidos tradicionalmente à maternidade, buscando neles um refúgio para suas dores. Ora elas reforçam esses significados, ora os ressignificam, mostrando, assim, a ambiguidade do papel da religião nas concepções de gênero e de maternidade. Considerando essa realidade, este artigo tem por objetivo contribuir com a reflexão sobre a relação entre maternidade, gênero e religião em contextos de violência.

A pesquisa aqui apresentada é o recorte de uma investigação mais ampla1, sobre mortes violentas e o sentido da fé para quem fica, cujo objetivo era descrever o papel da religião como fornecedora de sentido para os familiares das vítimas de mortes violentas. Na intenção de verificar essa realidade, Goiânia e as suas principais cidades circunvizinhas fizeram parte da pesquisa empírica. A mesma aconteceu por meio de entrevistas semiestruturadas, realizadas com familiares de vítimas de homicídios, suicídios e acidentes de transportes terrestres. As entrevistas foram realizadas no período de janeiro a maio de 2018, no Instituto Médico Legal de Aparecida de Goiânia, cidade metropolitana de Goiânia, Goiás, no momento em que os familiares vinham reconhecer os corpos de seus entes que haviam sido mortos, vítimas de violência. Para a pesquisa de campo foram selecionados vinte e cinco participantes/familiares de vítimas de mortes violentas. Os mesmos responderam a um questionário contendo duas partes: vinte e quatro questões fechadas sobre o perfil socioeconômico e a dimensão sociorreligiosa, abrangendo dados pessoais, capital cultural, profissão, posição religiosa/espiritual, origem, posicionamentos sociais e prática religiosa. A segunda parte compunha-se de dados qualitativos: no mesmo questionário apresentado à totalidade dos participantes, foram incorporadas treze questões abertas, visando coletar informações sobre a importância da religião como atribuidora

O projeto de pesquisa para esta investigação foi submetido ao Comitê de Ética em Pesquisa da PUC Goiás e obedeceu rigorosamente às regras do CONEP (CAAE 84984817.2.0000.0037, recebendo parecer favorável número: 2.551.209). 
de sentido. Na fase de tabulação dos dados quantitativos foi utilizado o software Statistical Package for the Social Sciences SPSS. Seguindo-se a orientação de Maria Cecília Minayo (2014), fez-se a consideração dos dados por meio de procedimentos estatísticos, obedecendo a seguinte sequência: definição das variáveis, a partir dos dados coletados no questionário e na Escala Likert; representação gráfica das amostras de dados relativas às variáveis obtidas no questionário e na escala Likert; apresentação dos resultados provenientes da aplicação dos testes estatísticos; análise dos dados representados nos gráficos e tabelas. A análise dos dados qualitativos, das questões abertas, foi realizada a partir da consideração das ideias-chave, repetições e incidências de argumentações sobre os diferentes aspectos que se destacaram nas respostas das participantes. Seguindo as orientações de Maria Aparecida Viggiani Martins e Joel Bicudo (2003) e de Maria Cecília Minayo (2014), a análise de dados foi feita em quatro momentos: a) o sentido do todo - leitura da descrição do relato após a transcrição sem buscar qualquer interpretação; b) nova leitura e outras mais para discriminar as unidades de significado, anotando-as diretamente no texto para ir focalizando o fenômeno que está sendo pesquisado; c) transformação das expressões cotidianas do sujeito - o objetivo é chegar às categorias; d) síntese das unidades de significado. No transcorrer da análise, percebeu-se que as mortes violentas atingem de forma mais cruel a parcela mais fragilizada da sociedade brasileira: os jovens pretos, pardos e pobres da periferia, as mulheres e as minorias sexuais. Destacou-se que, no momento de enfrentamento do sofrimento e do desespero diante da morte violenta de seu ente amado, a religião e seus eficientes mecanismos simbólicos são as estruturas mais poderosas para combater a brutalidade da morte, as inseguranças, os medos, a profunda sensação de vazio e, principalmente, atribuir sentido para uma vida futura sem a presença física do ente querido.

O recorte aqui apresentado refere-se aos depoimentos de seis mulheres-mães. Fizemos esse recorte, com o objetivo de verificar quais concepções de maternidade se expressam nesse contexto e como a religião se faz presente na composição de tal concepção, bem como na forma de compreensão da experiência de contato com a morte violenta de um/a filho. São elas²:

Os nomes são fictícios, para garantir a privacidade das entrevistadas. 


\begin{tabular}{|l|l|l|l|l|l|l|}
\hline $\begin{array}{l}\text { Nome e } \\
\text { parentesco }\end{array}$ & Idade & Profissão & $\begin{array}{l}\text { Cor/ } \\
\text { Etnia }\end{array}$ & Grau de Esc. & Tipo de Morte & Religião \\
\hline Maria Jocasta & 41 & Diarista & Negra & Analf. & Homicídio & Protestante \\
\hline Maria Francisca & 38 & Diarista & Parda & Semianalf. & Homicídio & Protestante \\
\hline Maria Laura & 40 & D. de Casa & Parda & Ens. Sup. & $\begin{array}{l}\text { Acidente de } \\
\text { Trans. }\end{array}$ & Protestante \\
\hline Maria Rosa & 32 & $\begin{array}{l}\text { Aux. Lim- } \\
\text { peza }\end{array}$ & Negra & $\begin{array}{l}\text { Fundam. } \\
\text { Incomp. }\end{array}$ & Homicídio & Protestante \\
\hline $\begin{array}{l}\text { Maria Mada- } \\
\text { lena }\end{array}$ & 44 & Serv. Públ & Negra & Ens. Médio & Homicídio & Protestante \\
\hline Maria da Silva & 51 & D. de Casa & Parda & Ens. Médio & Feminicídio & Católica \\
\hline
\end{tabular}

O presente artigo se apresenta estruturado da seguinte forma: a religião como um elemento estruturante das concepções de gênero e de maternidade; as concepções de maternidade, entrecruzadas com as crenças e práticas religiosas das mulheres entrevistadas, em contexto de violência.

\section{RELIGIÃO COMO ELEMENTO ESTRUTURANTE DAS CONCEPÇÕES DE GÊNERO E DE MATERNIDADE}

São muitas as autoras que têm trabalhado gênero como categoria de análise sob diversas perspectivas. Para fins desta análise, consideramos gênero como "um conjunto de arranjos através dos quais uma sociedade transforma a sexualidade biológica em produto da atividade humana, e na qual estas necessidades sexuais transformadas são satisfeitas" (Gayle RUBIN, 1993, pp. 2 e 23). Segundo Joan Scott (1991, p. 14), "o gênero é um elemento constitutivo de relações sociais baseado nas diferenças percebidas entre os sexos, e o gênero é uma forma primeira de significar as relações de poder". Para essa autora, utilizar a categoria gênero em análises sociais significa rejeitar explicitamente as justificativas biológicas para as desigualdades nas relações sociais entre os sexos: “o uso do 'gênero' coloca a ênfase sobre todo um sistema de relações que pode incluir o sexo, mas que não é diretamente determinado pelo sexo nem determina diretamente a sexualidade" (Joan SCOTT, 1991, p.

Assumimos a religião apresentada pelas entrevistadas. 
5). Portanto, como afirma Michèle Ferrand (1987, p. 61), nem a anatomia nem a natureza explicam o domínio das mulheres pelos homens, mas essa dominação social reinterpreta, utiliza, atribui um sentido à diferença biológica, e em particular, à maternidade e à paternidade. Entendemos que considerar a categoria gênero nas análises das relações sociais nos permite refletir sobre as concepções de maternidade e das relações das próprias mulheres com esse papel social, bem como sobre o papel da religião na construção de uma determinada concepção de maternidade, permeada pelas dimensões das relações de gênero.

Sobre a religião, Pierre Bourdieu (1998, p. 46) afirma que ela, graças ao seu efeito de consagração ou de legitimação de diferentes situações, permite a legitimação de todas as propriedades características a um estilo de vida de um grupo ou de uma classe, na medida em que ela ocupa uma posição determinada na estrutura social. No caso desta investigação, a religião é entendida como "um sistema de símbolos" (Clifford GEERTZ, 2008, p. 104) estruturado, cuja estrutura corresponde à estrutura social na qual está inserida (Pierre BOURDIEU, 1998, pp. 45 e 33) e cujo conteúdo é uma síntese do ethos de um povo (Clifford GEERTZ, 2008, pp. 103-104). Mas ela é também, graças ao seu efeito de consagração ou de legitimação de diferentes situações, um sistema de símbolos estruturante, e por esse motivo ela delimita o campo do que pode ser discutido em oposição ao que está fora de discussão (Pierre BOURDIEU, 1998, p. 45-47). Essas propriedades da religião apontadas pelos autores referidos ajudam-nos entender a importância de considerarmos a interação entre as ideias religiosas e outras afirmações presentes em outros espaços socioculturais sobre a maternidade. Ou seja, se, como afirma Elisabeth Badinter (1985), o amor materno não é algo natural, mas construído socialmente, não se pode duvidar do importante papel das ideias oriundas de diferentes tradições religiosas que compõem nossa cultura nessa construção.

Tendo presentes as afirmações acima sobre a interação entre os diferentes aspectos (gênero, religião) que constituem a concepção de maternidade, trazemos aqui, a título de exemplo, algumas ideias religiosas sobre a maternidade, veiculadas na mídia na atualidade em sites específicos de diferentes expressões religiosas. 
Iniciamos por apresentar ideias veiculadas na Religião de Deus, do Cristo e do Espírito Santo, ao afirmar que a relação mãe-filho é formada no Mundo Espiritual, antes mesmo de nascermos na Terra. Por esse motivo, a maternidade é um exercício de profundo amor e cuidado. Exercê-la, traz muita felicidade, mas também grandes responsabilidades e preocupações ao casal ou ao lar que têm um compromisso com aquele ser. Dessa forma,

como uma homenagem a todas as abnegadas mães e a fim de ajudar nessa longa e gratificante jornada que é a criação dos filhos e no fortalecimento dos lares (...), lembramos que, na Religião Divina, a maternidade possui um significado especial e abrangente, pois o que mais aproxima a mulher de Deus é o sentido da maternidade. Mesmo quando não seja Mãe carnal, há muitas formas sublimes de ser Mãe, inclusive dar à luz grandes realizações em prol da Humanidade4.

Trazemos, também, uma referência ao tema, veiculada em um site destinado a informações sobre o Islã. Diz-se que "uma das atribuições da mulher é obter o conhecimento e a sabedoria, principalmente para a maternidade" Al Bukai, "O paraíso jaz aos pés de uma mãe, afirmou o profeta Maomé em uma Hadith. E, para a doutrina islâmica, a posição da mãe é três vezes superior à do pai. Os laços entre mãe e filho são encorajados em detrimento aos laços matrimoniais".

Terminamos este item apresentando, de forma resumida, cinco afirmações do Papa Francisco, principal líder da Igreja Católica, sobre a maternidade ${ }^{6}$. Para ele: 1 . Através da maternidade, a mulher participa do

4 José de Paiva Netto. Laços espirituais entre mãe e filho. Depoimento do presidente-pregador da Religião de Deus, do Cristo e do Espírito Santo. Publicado pela Redação do site da Igreja, dia 08/05/2018. Disponível em https://www.religiaodedeus.org/pt/religiao-no-dia-dia/lacos-espirituais-entre-mae-e-filho visitado dia 23/04/2021.

5 Entrevista com o Chaikh Mohamad Al Bukai (Liga da Juventude Islâmica do Brasil). In: Islamismo. Disponível no site https://vidaconcebida.com.br/islamismo.html visitado dia 23/04/2021.

65 ensinamentos do Papa Francisco sobre a maternidade. Publicado no site da Canção Nova, dia 09/05/2019. Disponível no site https://blog.cancaonova.com/vocacional/5-ensinamentos-papa-francisco-sobre-maternidade/ visitado dia 23/04/2021. 
mistério da criação. Ela (a mãe) colabora com Deus para que se verifique o milagre duma nova vida; 2. As mulheres grávidas devem cuidar da alegria da maternidade, pois aquela criança merece a alegria. Portanto, "não permitas que os medos, as preocupações, os comentários alheios ou os problemas apaguem esta felicidade de ser instrumento de Deus para trazer uma nova vida ao mundo"; 3. A maternidade é testemunho de ternura e dedicação, pois "De fato, as mães são o antídoto mais forte contra o propagar-se do individualismo egoísta (...). São elas que testemunham a beleza da vida". Sem dúvida,

uma sociedade sem mães, seria uma sociedade desumana, porque as mães sabem testemunhar sempre, mesmo nos piores momentos, a ternura, a dedicação, a força moral; 4 . A mãe que ampara o filho com a sua ternura e compaixão, ajuda a despertar nele a confiança, a experimentar que o mundo é um lugar bom que o acolhe, e isso permite desenvolver uma autoestima que favorece a capacidade de intimidade e a empatia (...). As capacidades especificamente femininas - em particular a maternidade às mulheres-mães deveres, já que o seu ser mulher implica também uma missão peculiar nesta terra, que a sociedade deve proteger e preservar para o bem de todos; 5 . Por esses motivos, queridas mães, obrigado, obrigado por aquilo que sois na família e pelo que dais à Igreja e ao mundo.

Esta breve apresentação das ideias religiosas sobre a maternidade nos permite perceber o quanto essa função é amplificada, trazendo com ela uma série de consequências para a vida cotidiana das mulheres, sejam elas mães ou não.

Segundo Anthony Giddens (1993) a "invenção da maternidade" faz parte de um conjunto de influências que afetaram as mulheres a partir do final do séc. XVIII: o surgimento da ideia de amor romântico; a criação do lar, a modificação das relações entre pais e filhos. O autor assinala que no final do séc. XIX houve um "declínio do poder patriarcal” com o "maior controle das mulheres sobre a criação dos filhos" referindo-se a um deslocamento da "autoridade patriarcal para a afeição maternal" (Anthony GIDDENS, 1993, p.53). Ele destaca como novo, neste período, a forte associação da maternidade com a feminilidade. 
Autoras como Nancy Chodorow (1980) e Michèle Ferrand (1994) têm construído e alimentado o debate teórico em torno do processo de mudanças que está ocorrendo nos padrões e experiências contemporâneas da maternidade nos últimos trinta anos. Este modelo se consolidou em uma ideologia que passou a exaltar o papel natural da mulher como mãe, atribuindo-lhe todos os deveres e obrigações na criação do(a)s filho(a)s e limitando a função social feminina à realização da maternidade. Nesse sentido, afirma Judith Butler (2003, p. 136), que não é justo que se imponha "ao corpo das mulheres a obrigação compulsória de reproduzir [...] o desejo de dar à luz resulta de práticas sociais que exigem e produzem esses desejos, para levar a efeito seus objetivos reprodutivos". E Laura Davis Matar e Carmem Simone Grilo Diniz (2012) discutem que:

a maternidade foi, e, em alguma medida, segue sendo, uma identidade forçada das mulheres já que, com frequência, não têm controle sobre seus corpos. Soma o fato de que, ainda que haja uma mudança lenta em curso, no sentido de uma melhor e mais equilibrada divisão do trabalho doméstico entre homens e mulheres, as últimas ainda são as principais responsáveis pelo cuidado com os filhos, o que as mantém restritas à esfera doméstica, dependentes dos homens ou do Estado (Laura Davis MATTAR; Carmem Simone Grilo DINIZ, 2012, p.108)

Entretanto, como alertam Yvonne Knibielher e Catherine Fouquet (1977), a realização desse ideal de maternidade era impossível para as mulheres pobres:

As classes dominantes que reinventam a maternidade como vocação feminina exclusiva estão em contradição absoluta com a realidade concreta: muitas mulheres trabalham no séc. XIX e devem assumir sua maternidade nas condições mais difíceis. A distância é imensa entre o ideal descrito e sonhado da mãe educadora, consagrada em tempo integral às suas crianças, e a vida cotidiana das mães de origem modesta (Yvonne KNIBIELHER; Catherine FOUQUET, 1977, p.210)

Na mesma perspectiva, aponta o pensamento de Adriana Tanese Nogueira (2017), para quem a realidade das mulheres, como sujeitos 
humanos que vivem uma tripla jornada de trabalho que lhes tira o sono, a saúde e a alegria não é reconhecida. Quando mencionada é tachada como "egoísmo", afundando a mulher-mãe num poço sem fim de culpa e vitimismo, ou raiva sufocada. Essa é a situação das mulheres colaboradoras desta pesquisa.

\section{AS CONCEPÇÕES DE MATERNIDADE, ENTRECRUZADAS COM AS CRENÇAS E PRÁTICAS RELIGIOSAS DAS MULHERES ENTREVISTA- DAS, EM UM CONTEXTO DE VIOLÊNCIA}

A precariedade humana é escancarada pela brutalidade das mortes violentas de vítimas de acidentes de trânsito, homicídios, suicídios. De acordo com o Atlas da Violência de 2018, produzido pelo Instituto de Pesquisa Econômica Aplicada (IPEA) e o Fórum Brasileiro de Segurança Pública (FBSP), o número de 62.517 assassinatos cometidos no país em 2016 coloca o Brasil em um patamar 30 vezes maior do que o da Europa. Só na última década, 553 mil brasileiros perderam a vida por morte violenta. Ou seja, um total de 153 mortes por dia. Essa realidade é descrita pela colaboradora Maria Filomena, 52 anos, tia de um rapaz de 19 anos, morto em uma chacina7:

Acabô, meu filho, acabou! A família tá destruída. Não sei se minha irmã vai aguentá, sabe? É o segundo filho que ela perde dessa maneira. $O$ irmão mais velho dele morreu do mesmo jeito, tem uns dez anos. Do mesmo jeito, cheio de tiro. Ela tá em casa desmaiada de dor. A família desmoronou, não dá mais. É muita dor, nossa meu Deus! É muita dor pra suportá. Com o outro eu achei que ela ia fazê uma besteira. Com esse agora, agente tá com muito medo da nossa irmã fazê besteira. Só Deus, meu filho, só Deus.

A mortalidade pela via da violência (homicídios, suicídios e mortes no trânsito), em particular os homicídios dolosos, cresce a cada ano. Os números totais destas mortes no Brasil equivalem aos das estatísticas

\footnotetext{
7 Inserimos este depoimento por fazer menção ao possível sentimento que a mãe da pessoa assassinada terá, ao saber da notícia da morte de seu segundo filho nessas circunstâncias. Para nos aproximarmos o máximo possível dos significados expressados nos depoimentos, optamos por transcrever tal qual falado pelas colaboradoras, sem as devidas correções das concordâncias gramaticais.
} 
de guerras. Entre os anos de 1980 e 2012, morreram no país: 1.202.245 pessoas vítimas de homicídio; 1.041 .335 vítimas de acidentes de transporte; 216.211 suicidaram-se. As três causas somadas totalizam 2.459.791 vítimas. Estes dados compõem o criterioso levantamento realizado pelo pesquisador Julio Jacobo Waiselfisz (2018) autor do Mapa da Violência 2018 - os Jovens do Brasil.

Ainda segundo esse estudo, em 1980 o quadro de mortes se apresentava desta forma: 20.365 (Transporte); 3.896 (Suicídios) e 13.910 (Homicídios). Em 2016 estes números saltaram para: 38.265 (Transporte); 11.433 (Suicídios) e 62.517 (Homicídios). É evidente que as causas ligadas ao aumento da violência não se atribuem, unicamente, ao crescimento populacional ou à complexidade da vida moderna. Observa-se que o número de mortes ligadas ao transporte quase dobrou, enquanto o número de suicídios mais que triplicou. Destaca-se que o número de homicídios mais do que quadruplicou nos últimos 36 anos.

Compreender e encaixar a morte no fluxo da existência constitui importante mecanismo de defesa, mas não é o único. No ambiente do IML, poucas horas ou minutos depois da comunicação da morte ao/à familiar, não é possível processar adequadamente as dores sentidas. Muitos/as ainda estão numa espécie de estado de suspensão, perplexos/as, incrédulos/as diante do ocorrido. Uma mãe que não pode ser entrevistada, devido ao seu estado emocional alterado, gritava desesperadamente pelo salão do instituto: “Ai, meu Deus! Ai, meu Deus! Meu menino não! não é meu filho, não é meu filho! Meu garoto não tá morto! Meu garoto não tá morto! Meu garoto não tá morto!"”. Os gritos dessa mãe são compreensíveis, uma vez que, considerando as informações sobre as representações sociais ${ }^{8}$ da maternidade em nossa cultura, aceitar que o filho esteja morto devido a um assassinato é, de certa forma, deixar morrer junto uma parte de seu ser: a maternidade. Isto porque as mães, conforme são representadas em nossa cultura, ou criam bem seus filhos para que não se metam em encrencas, ou os protegem muito

Segundo Serge Moscovici (1978, p. 50), as Representações Sociais são conjuntos de conceitos, valores, afirmações e explicações, "teorias" do senso comum, "ciências" coletivas sui generis, pelas quais se procede à interpretação e mesmo à construção de realidades sociais; e o seu status, é o de uma produção de comportamentos. 
para que não sejam expostos à violência. Nessa forma de representar a mulher-mãe, um filho morto violentamente representa o fracasso da mãe e da maternidade.

Como as pessoas entrevistadas associam a vida/morte de seus filhos às crenças e práticas religiosas?

\subsection{O AMOR DE DEUS, O AMOR DA MÃE E O LIVRE ARBÍTRIO DO/A FILHO/A}

Considerando o peso conferido ao papel da mãe na construção do indivíduo social e também da própria sociedade, algumas questões bem complexas se põem. Uma delas é a questão do livre arbítrio. As mães fazem o melhor para transmitir a seus filhos os valores condizentes com as expectativas da sua sociedade naquele período histórico, mas nem sempre os/as filhos/as correspondem a esse investimento das mães. 0 livre arbítrio, como algo criado por Deus, se apresenta, de certa forma, como um álibi para as mães cujos filhos não seguiram suas orientações: não são elas que são responsáveis pelos erros de seus filhos, que os levaram à morte. Foi Ele (Deus) que os deixou livres para escolherem o que e como queriam ser, como argumenta Maria Francisca:

Então, todo mundo tem um plano perfeito feito por Deus. É claro que quando Deus coloca a gente na Terra, Ele te dá livre arbítrio, daí cada um escolhe o que você vai criar. Infelizmente muita gente escolhe errado. Se todo mundo seguisse os planos de Deus, não havia sofrimento na terra, você entende?

O luto em si já é algo difícil para os familiares processarem mas quando resultante de uma morte violenta de um filho, ele se apresenta às mães como um fardo gigantesco, que precisa de muita religião, para se tornar suportável e para que elas não venham a sucumbir mediante sua própria dor. E a religião que pode fornecer os significados necessários, às vezes, se mostra em sua ambiguidade: o mesmo Deus que deixa o livre arbítrio também pode punir com a morte seus filhos, quando "cometem o pecado" e não seguem os valores ensinados. No depoimento de Maria Luíza, vemos: 
Eu acho que...eu não sei...eu acho que foi da cabeça dele mesmo, porque eu ensinei muita coisa boa pra ele, mas ele não quis seguir. Da cabeça dele mesmo que ele teve essa má intuição de fazer coisa ruim. Vontade de dinheiro fácil. Ele já envolveu com drogas, acho que a morte dele foi por isso... alguma coisa sobre isso, acho que é isso aí. Eu vivia dizendo pra ele: 'o salário do pecado é a morte', mas ele não me ouviu.

De acordo com os depoimentos das mães, os/as jovens tinham sido alertados/as inúmeras vezes sobre o caminho que haviam tomado. Alguns tinham sido presos e cumprido alguma forma de privação da liberdade, como menores ou maiores de idade. As famílias, sabendo do perigo, já estavam cientes dos riscos enfrentados pelas vítimas da violência. Essas expressões podem ser notadas nos argumentos da entrevistada Maria Rosa:

Muitas das vezes a própria pessoa procura as coisas ruins, um caminho perigoso, cheio de armadilhas. Se a gente puder evitar ao máximo né, muitas coisas são evitáveis. Você só é atacado pelo leão se você chegar perto dele, não é mesmo? Eu acredito que muitas das vezes as companhias que a gente escolhe. Ninguém é obrigado a escolher uma companhia perigosa para andar junto pelas ruas, né. A escolha é da gente, sabe! Filho que não olha pros conselhos dos familiares, do pai e da mãe acaba sofrendo, inclusive com a morte.

E, segundo Maria Jocasta:

Eu acho que Deus sempre esteve presente na vida dele, mas ele vivia se afastando de Deus. Eu levava ele pra igreja, ele melhorava um tempão, ficava bem, trabalhava e até tava querendo estudar de novo, queria fazer engenharia. Mas de repente aparecia essas amizades lá em casa e botava tudo perdido de novo. Até que Deus deu um jeito de levá ele pra junto dele. Deus levou meu filho pra ele não dá mais trabalho aqui na terra.

As palavras de Clifford Geertz (2008) nos ajudam compreender o recurso do livre arbítrio acionado pelas mulheres-mães entrevistada. Para o autor, os símbolos religiosos estabelecem uma harmonia fundamental 
entre um estilo de vida particular (ethos) e uma metafísica específica (visão de mundo). A religião ajusta as ações humanas a uma ordem cósmica e projeta imagens desta ordem cósmica no plano da experiência humana, o que ocorre no cotidiano de cada povo. Nessa perspectiva, da mesma forma que Deus ou o destino dão ao ser humano um plano pronto, perfeito ou imperfeito, cabe ao indivíduo através da sua livre escolha, acabar traçando outro plano para a sua vida. Acertado ou não, correto ou errado, positivo ou negativo, o homem é livre para escolher, sendo que, às vezes, certas escolhas são fatores determinantes para sua morte violenta. Nesse sentido, argumenta Maria Madalena: "eu acredito que tem dois caminhos, um que leva para um lugar certo e bom e outro que leva para um lugar errado e que causa o mal. Mas quem escolhe é você, entende? Por isso você colhe o que plantou. Meu filho tá aqui hoje por causa disso, do caminho que ele seguiu".

Apesar de todo amparo e atenção, os filhos crescem e começam a escolher seus caminhos, amizades, lugares, alimentos, relacionamentos, enfim, a desenhar com seus próprios traços as suas vidas. Longe dos olhares maternais cada qual é lançado à própria sorte, aos desígnios divinos, ao destino ou aos resultados de suas próprias escolhas. Como afirma Maria da Silva: "Quando ele era criança eu dizia e ele obedecia, depois de grande ele nunca mais me ouviu".

Embora o livre arbítrio tenha sido evocado para fornecer algum significado ao que aquelas mães estavam experienciando naquele momento, ele parece ter sido insuficiente. Nesse sentido, Clifford Geertz (2008), afirma que há uma dependência do homem aos símbolos e sistemas simbólicos. Estes parecem ser decisivos para que o próprio ser humano seja viável enquanto criatura, havendo quase nenhuma transigência à sugestão de que a capacidade de criar, apreender e utilizar símbolos pode falhar. Se isto acontecesse, nos diz o autor, seria o caos - um túmulo de acontecimentos ao qual faltam interpretações e interpretabilidade. Três são os pontos no qual o caos ameaça o ser humano: 1. Nos limites de sua capacidade analítica - a maioria dos seres humanos não consegue deixar sem esclarecimento problemas não esclarecidos, uma inquietação profunda ocorre quando há o fracasso do aparato explanatório; 2. nos limites de seu poder de suportar - a religião 
oferece a capacidade de compreender o mundo e definir as emoções, permitindo suportá-las. Não saber como interpretar as emoções causa um sofrimento ainda mais profundo; 3 . nos limites de sua introspecção moral - quando algo dificulta a possibilidade de fazer julgamentos morais ditos corretos, de utilizar o sistema simbólico que nos oferece o aparato ético e moral que nos parece mais adequado naquele momento. Em resumo, a difícil compreensão de certos acontecimentos leva à dúvida, que se torna bastante desconfortável, quanto à existência de uma ordem de mundo verdadeira. Contudo a religião elabora, em contraponto a toda esta dúvida, uma ordem genuína do mundo que dará conta das eventuais ambiguidades. Nesse sentido, a religião pode ser entendida como uma forma de conhecimento do mundo.

A religião, como destaca Clifford Geertz (2008), pode se apresentar como um recurso imprescindível, para que as mães possam suportar as dores daquele momento crucial, quando a morte se apresenta a elas em toda sua crueza. A entrevistada Maria da Silva relata: "Meu Deus! É o meu segundo filho que morre assassinado. O outro morreu faz, exatamente, dez anos." Como essa mulher é capaz de assimilar dois golpes no intervalo de dez anos? Como essa mãe pode se manter segura, olhar para seus outros dois filhos e ter confiança que eles não terão a mesma sina cruel dos irmãos? O depoimento dessa mãe pode ser entendido à luz do que afirma Jacques Derrida (2018), ao dizer que a morte é o fim de tudo que era único, singular, insubstituível. A morte é o fim do mundo, a morte é:

o mundo depois do fim do mundo. Porque de cada vez, e de cada vez singularmente, de cada vez insubstituivelmente, de cada vez infinitamente, a morte não é nada menos que um fim do mundo. Não somente um fim entre outros, o fim de alguém ou de alguma coisa no mundo, o fim de uma vida ou de um vivente. A morte não põe um termo a alguém no mundo, nem a um mundo entre outros, ela marca de cada vez, de cada vez no desafio da aritmética, o fim absoluto do único e mesmo mundo, do que cada um abre como um só e mesmo mundo, o fim do único mundo, o fim da totalidade do que é ou pode apresentar-se como a origem do mundo para um determinado e único vivente - seja ele humano ou não (Jacques DERRIDA, 2008, p. 16-17). 
$E$, nos casos em que estamos analisando, as mortes dos filhos dessas mulheres representam, além do fim do mundo em geral, o fim de um mundo em particular: o mundo da maternidade, o mundo da mãe, pois pelo que apreendemos da nossa cultura, uma mulher sem a maternidade e uma mãe sem o filho não se reconhecem e nem são reconhecidas como seres humanos, como pessoas. Com os assassinatos de seus filhos, é o mundo da maternidade e das mães que estão sendo mortos. Como todas as entrevistadas confessaram a fé cristã, não foi de se estranhar o pecado ser uma figura importante nas respostas. A culpa esteve presente de forma explícita e nas entrelinhas. O sentimento de culpa dos/as que ficaram, por não terem feito mais do que fizeram. $O$ sentimento de culpa colocado sobre as vítimas, por terem flertado com a morte, de alguma forma. A culpabilização, segundo Jean Delumeau (2003) é uma característica do mundo ocidental presente desde os séculos XIII e XVIII. Afirma o autor:

Meu livro não deve, portanto, ser compreendido como uma recusa da culpabilidade e da necessária consciência do pecado. Em compensação, eu creio que ele fará sobressair a presença de uma pesada "superculpabilização" na história ocidental. Entendo por "superculpabilização" todo discurso que maximiza as dimensões do pecado em relação ao perdão. É essa desproporção - e somente ela - que fornece a matéria da presente pesquisa (Jean DELUMEAU, 2003, p. 15).

Considerando o peso conferido à maternidade, e todas as obrigações correlatas à função de mãe, não nos parece estranho que as mulheres-mães de pessoas vítimas de mortes violentas venham a se sentir culpadas. Em nossa realidade sociocultural atual, por mais que as mulheres-mães se empenhem para cumprir a contento o que delas é esperado, nunca o conseguirão, pois o que se espera de uma mãe é praticamente impossível de se conseguir. Essa situação se torna muito mais grave, quando as mulheres-mães não encontram ambiente socioeconômico e cultural adequado para que seus filhos possam crescer e se formar enquanto seres humanos. 


\subsection{MEU FILHO SOFREU E MORREU, COMO CRISTO FOI CRUCIFICA- DO E MORREU. MAS ELE(S) VIVE(M)}

Realmente a vida e a morte não dependem da existência humana para existirem, mas esse indivíduo que se desenvolveu por meio de um processo bio-neuro-histórico foi capaz de desenvolver abstrações do mundo imanente, criando possibilidades de transcender suas relações com vida e com a morte. O desenvolvimento da religiosidade, da fé e de suas compreensões sobre a dor, o sofrimento, e a morte são ricamente elaborados pelas diversas culturas e épocas, sendo que os familiares respondem às demandas dos seus próprios contextos sociais. Nesse sentido, as respostas das entrevistadas sobre o que estavam sentindo naquele momento expressam esses sentidos. Dentre elas, duas expressaram a palavra "sofrimento", outras duas a palavra "revolta" e uma a palavra "impotência". Clifford Geertz (2008, p. 77) nos ajuda entender essas expressões das mulheres-mães ao afirmar que "o problema do sofrimento recai facilmente no problema do mal, pois se o sofrimento é normalmente muito cruel, embora nem sempre, ele é também considerado moralmente imerecido, pelo menos para o sofredor". E Zygmunt Bauman (2008, p. 64), ao falar sobre a fragilidade e a morte dos laços humanos, afirma que:

A fragilidade dos vínculos humanos é um atributo proeminente, talvez definidor da vida líquido-moderna. A enorme fragilidade desses vínculos e a frequência com que são rompidos servem como lembrete constante da mortalidade que caracteriza a existência humana. Não há muito sentido em questionar a validade de se igualar a perda de um parceiro pela separação com a perda "verdadeiramente final" causada pela morte física - o que conta é que, em ambos os casos, "um mundo", sempre "singular", desaparece - e que tanto a vontade quanto a esperança caem frente ao desafio do fim.

Quando perguntamos “onde você está buscando forças para enfrentar este momento?”, duas palavras se destacaram: Deus e Família. As evocações chamaram atenção por dois motivos principais. Em primeiro lugar se destacou a fragilidade natural das pessoas diante do enfrentamento da morte violenta de um parente, ou seja, a debilidade, 
a impotência, a incapacidade de negociação com a morte. Em segundo lugar a busca por um porto seguro, um norte físico e simbólico que se faz determinante para a retomada de sentido e ancoragem em meio ao turbilhão. Nestes casos específicos os portos são: Deus e Família. No entanto, não é qualquer imagem de Deus que é evocada para fornecer sentido à dor. Trata-se de um Deus sofredor, que foi brutalizado, humiIhado, torturado, sua dignidade e humanidade desprezadas, pregado e morto na cruz, tal como o filho delas, que vieram reconhecer depois de serem mortos violentamente. Jurgen Moltmann descreve o sofrimento de Cristo na Cruz e seu grito de desespero, para comprovar que Deus não abandona seus filhos na hora mais tenebrosa, mas reforça sua presença esperançosa na dor e no sofrimento dos seus:

Quando li o grito de Jesus ao morrer: "Meu Deus, por que me abandonaste?", soube com certeza: está ali o único que me compreende. Comecei a compreender o Cristo atribulado, porque sentia que era compreendido por ele: o irmão divino na aflição, que leva consigo os cativos em seu caminho para a ressurreição. Recobrei o ânimo de viver. Fui tomado de uma grande esperança (2002, p. 12-13).

Em conformidade com o que foi descrito acima, é justamente no exemplo de Cristo que a fé e a esperança na vida, na dor, no sofrimento e na morte se renovam a cada dia. Mas, mesmo a fé na eternidade sendo um mecanismo de defesa simbólico muito eficiente, a morte - em si continua causando grande temor, dor e sofrimento, inclusive naqueles que creem na eternidade da existência. É possível constatar as inseguranças e os medos sobre a morte nas falas que seguem: "A morte é uma dor sem cura". "A morte é pra todos, não tem como evitar". "A morte é uma força incontrolável". "Uma dor, uma dor, não sei". "A morte é ir para a vida eterna". "Ela tira da gente nosso maior amor". "A morte é um caminho sem volta". "A morte é escuridão". Algumas entrevistadas definiram a morte como uma força inegociável, outras disseram que a morte é um processo natural e democrático, como uma necessidade do próprio existir. Muitos/as associaram a morte a um sofrimento terrível. É esse Deus, nessa condição, que se apresenta às mães como um caminho certo, um porto seguro, uma luz para guiar a vida delas. Subjacente à 
associação entre seus filhos e o Deus morto na cruz, os depoimentos dessas mulheres-mães expressam também uma esperança: assim como Ele, que se fez homem, assumindo toda fragilidade humana se tornou grandioso pela sua ressurreição, também seus filhos que tanto sofreram antes e agora, com a morte, também poderão se tornar grandiosos, pela salvação e, como Ele, poderão vencer a morte em sua totalidade. Foi justamente essa vivência dolorosa, enfrentada por Jesus, que chamou atenção na fala da entrevistada Maria Luiza:

Meu filho, Jesus sofreu muito, sentiu muita dô na cruz. Tudo para salvar a gente, viu! Do mesmo jeito que Deus sofreu pela gente, a gente tem que sofrer, né, faz parte da vida. Da forma que Jesus penou, todo mundo tem que pená para pagá os pecado. Deus pagô os pecado nosso, a gente paga o da gente.

De acordo com a entrevistada Maria Luiza é justamente a crença em um Deus que amou de forma incondicional os seus filhos, um Deus que deu seu fruto em holocausto para o perdão dos pecados humanos, um Deus que se fez homem, viveu, sofreu e morreu, que lhe dá forças em seu sofrimento atual, causado pela morte violenta de seu filho. Um "Deus fraco" que tem em sua "fraqueza" a sua maior fortaleza. Para essa mãe a cruz está vazia, Deus venceu a dor, o sofrer e a morte, como seu filho morto pelas mãos da força policial. Ambos estão salvos, ambos passaram pelo calvário e estão salvos - a religião cumpriu seu papel atribuidor de sentido, estabilizador da fluidez da vida.

Se no escopo pragmático punitivo, o castigo é uma forma de pena muito bem justificada, que direciona o/a castigado/a a compreender que seu suplício corresponde proporcionalmente ao seu ato corruptor da virtude 9 , essa forma de crer não está presente em todos os depoimentos. Se o castigo é a pena que deve ser paga pelo pecado praticado, pois o mesmo levou à degenerescência da vida, consequentemente à morte, para algumas mães a morte de seus/as filhos/as não representa esse castigo, uma vez que Deus é amoroso. O que leva à morte é o fato

\footnotetext{
9 "Para completar a mortificação da alma e livrá-la de cair em pecado é necessário combater a origem do mal que está em nós” (Adolphe TANQUEREY, 2018, p. 345).
} 
de que as pessoas, no caso seus filhos, não observam e não cumprem a vontade de Deus. Esse posicionamento pode ser percebido no depoimento da entrevistada Maria Jocasta:

Deus não dá pra gente o que a gente não dá conta de enfrentá. Deus é sábio, Deus é pai. Ele não qué o mal da gente, ele só qué o bem, o amô. A gente que faz bobagem, coisa errada. Mas se acontece coisa ruim não é castigo de Deus, agente que procura, né. Deus mostra o caminho do bem e a gente teima em i pro caminho errado. Mas o plano de Deus só é coisa boa. Misericórdia, né?!

É no contexto da crença de que Deus é amoroso, que não castiga, mas ensina, que a dor pode ser vista como positiva, na medida em que é um processo pedagógico, uma forma de aproximação desse Deus amoroso. Nesse caso, é preciso passar pela dor para alcançar a salvação ou elevação.

A fala das entrevistadas demonstrou que a simbologia do Deus débil ensina ao homem débil que a dor e o sofrer são condições da natureza humana, mas a lição última consiste em demonstrar que a cruz não é o fim, mas o começo da superação. O resultado final do sofrimento não é a morte, mas a vida eterna, o renascer no Deus (Pai, Amor, Poder e Justiça). Como reforça Maria Madalena: "Cada um tem a cruz que precisa carregar na vida".

A morte eu acho que é um, um, é um, como eu vou te dizer...eu acho que Deus te dá várias chances, entendeu, porém você tem que aproveitá-las de uma forma que Deus te dê mais oportunidades. Vou te dar um exemplo: Deus livrou meu filho várias vezes da morte, mas chega uma hora que, eu acho que, né...eu te dei várias oportunidades, mas você não quis mudar, agora não tem jeito mais, eu vou te levar.

Esta mãe, que procura compreender a morte violenta de seu filho, encaixa seu precoce falecimento num arcabouço justificado por sua visão transcendental do existir. Em sua concepção de fé, a mãe deixa claro que há um limite de chances, de oportunidades, de recomeços, pois quando findados a vida é derramada ao chão. 
Contudo a edificação da fé é uma particularidade dos seres humanos, ao qual faz parte Maria Madalena. Essa mãe chora a morte do filho, mas também elabora uma estrutura simbólica que permite compreender o próprio destino, a sina de seu ente e da própria humanidade que está propensa aos designíos que anunciam a vontade de seu Deus.

\subsection{ASSIM COMO JESUS, MEU FILHO SERÁ SALVO E RESSUSCITARÁ}

O problema do significado (o fato de existirem a perplexidade, a dor e o paradoxo moral) é um dos principais impulsionadores da crença religiosa. O axioma básico da perspectiva religiosa é que "aquele que tiver de saber precisa primeiro acreditar" (Clifford GEERTZ, 2008, p.81). Uma perspectiva religiosa é um modo de ver, um entre outros modos. Esta perspectiva difere da do senso-comum, da ciência e da estética. Ela repousa em uma aura "verdadeiramente real", a qual suas atividades simbólicas se devotam a produzir. No caso das entrevistadas desta investigação, o real é que seus filhos permanecerão entre elas. Vejamos o que elas dizem: "Acredito. Não sei, um paraíso junto a Deus. Eu tenho que crer nisso pra me fortalecer e dar força às pessoas que tão do meu lado, se a gente não acreditar?" (Maria Francisca); "Depois de pagar os pecados a alma dele vai para o Céu." (Maria Luiza); "Meu filho tá aqui do nosso lado! Mas logo ele vai ser levado para o céu". Ao ser perguntado por quem? Maria Luiza respondeu: "Pelos anjos do Senhô!".

Ao refletir sobre o sofrimento Clifford Geertz (2008, pp. 118-120), o vê como um desafio da experiência, em face do qual a totalidade do significado de um padrão particular de vida ameaça dissolver-se num caos de nomes que nada significam. Segundo este autor, o sofrimento representa um desafio apresentado à religião, uma vez que esta se identifica como aquela que ajuda as pessoas a suportarem situações de pressão emocional, abrindo fugas a tais situações e tais impasses que nenhum outro caminho empírico abriria, exceto através do ritual e da crença no domínio do sobrenatural.

A confiança das mães de que seus filhos estão salvos no paraíso Ihes dá possibilidades para seguirem em frente, na vida como ela a elas se apresenta. Neste sentido, essa forma de crer transcende o que Martin Heidegger (2012, p. 661) descreve como o ser do morto vivendo 
nos seres dos vivos através das memórias, das lembranças. Os mortos, nas representações dos parentes, vivem independentemente das vontades, das memórias e das lembranças dos vivos. Os mortos vivem, de acordo com a maioria dos familiares, pelo simples fato da existência não possuir finitude.

A consciência humana sobre o existir no mundo e além dele é por vezes muito complicada para ser compreendida, sendo a fé, para estes familiares, o caminho seguro para a compreensão e a resistência em meio aos males do mundo. Zygmunt Bauman (2008) argumenta que a fé, em particular a fé na continuidade da vida após a morte, atribui no existir dos indivíduos uma segurança carregada de sentido. Um "virar de ponta-cabeça" na realidade da morte que a transforma de um fato assustador em um caminho de esperança na eternidade.

Transformar a queda mais repugnante na mais jubilosa ascensão - foi realmente um movimento virtuoso. Não apenas conseguiu conciliar os mortais com sua mortalidade, mas também dotava a vida de um sentimento, um propósito e um valor que seriam enfaticamente negados ao veredicto da morte se este fosse deixado em sua direta e rígida simplicidade. Essa mudança transformou o poder destrutivo da morte num formidável poder de engrandecer a vida: ela atrelou a morte à carruagem da vida. Colocou a eternidade ao alcance do transitório, e pôs os autoconfessos mortais no controle da imortalidade (Zygmunt BAUMAN, 2008, p. 48).

O tomar consciência do existir e de todas as suas implicações não foi tarefa fácil para o ser humano, mas as possíveis ameaças foram devidamente rebatidas frontalmente com medidas protetivas. A referida conciliação dos mortais com a inevitável mortalidade é, sem sombra de dúvida, uma das maiores elaborações produzida pelo gênero humano. O processo de construção de sentidos à morte pode ser entendido à luz do pensamento de Clifford Geertz ao afirmar que

como problema religioso, o problema do sofrimento é, paradoxalmente, não como evitar o sofrimento, mas como sofrer, como fazer da dor física, da perda pessoal, da derrota frente ao mundo ou da impotente contemplação da agonia alheia algo tolerável, suportável (2008, p. 119). 
Segundo este autor, a religião ancora o poder de nossos recursos simbólicos para a formulação de ideias analíticas na concepção autoritária da forma total da realidade. Por outro lado, ela ancora o poder dos nossos recursos, também simbólicos, de expressar emoções, disposições, sentimentos, paixões, afeições, sensações numa concepção similar do seu teor difuso, seu tom e temperamento inerente. Aqueles que forem capazes de adotar os símbolos religiosos obterão uma garantia cósmica tanto para sua capacidade de entender o mundo, como para darem precisão a seu sentimento, uma definição às suas emoções que Ihes permita suportá-lo, soturna ou alegremente, implacável ou cavalheirescamente.

Georg Simmel ao debater sobre a salvação da alma descreve um aspecto muito importante que se aproxima da fala de um familiar que diz: "meu filho tá junto de Deus, na casa do Pai".

Há lugar para todos na casa de Deus, pois o máximo que o ser humano pode alcançar é também o mínimo que dele se espera e por isso, em princípio, não pode ser negado a ninguém. Mas a salvação nada mais é do que o fato de toda alma expressar por completo seu ser mais íntimo e nele realizar-se, sendo a imagem pura de si própria cujos contornos atravessam sua incompletude terrena (Georg SIMMEL, 2010, p. 5).

A mãe expressa a importância da sua fé para a reafirmação do sentido da morte e "a fé, assim compreendida, evidentemente exerce um papel muito importante na nossa santificação, pois, ao fazer-nos participantes do pensamento divino torna-se a base da vida sobrenatural" (Adolphe TANQUEREY, 2018, p. 471). Não há espaço para a dúvida, a morte não é um final vazio, tomado pela falta de caminho. Pelo contrário, a morte possui um propósito, uma razão de existir, uma lógica física e metafísica. Ter a morte como um total vácuo é dar espaço para o mundo líquido, para a ameaça da insegurança, da instabilidade. Portanto a morte e o depois da morte, para essas mulheres-mães, possui um sentido, uma via concreta, como "a casa de Deus". Essa e outras formas de compreensão da morte fortalecem-nas, pois "sem a fé a sociedade desmoronaria” (Georg SIMMEL, 2011, p. 8). É como diz 
Jean Delumeau: “À esperança de uma perfeita comunicação entre os habitantes da cidade celeste acrescenta-se hoje, entre os que recusam o niilismo escatológico, a convicção - ou o desejo? - de que aqueles que amamos permaneçam próximos de nós depois da morte" (2003, p. 490).

Apesar e diante dos soluços, as mães começam o processo, paulatino, de preservação da memória daquele que morreu. O verbo que outrora era conjugado no presente, agora precisa ser conjugado no passado. A trajetória do filho, seu nascimento - seus projetos e sonhos já não são mais possíveis. A história de vida chegou ao fim, portanto é preciso reescrevê-la, a partir de um novo capítulo inaugurado com a morte. E é como mãe que essas mulheres vão construir as memórias de seus filhos, como diz Maria da Silva: "Nunca vou esquecer o sorriso da minha filha". E Maria Jocasta continua:

Os médicos disseram que meu filho está morto! Eu sei que ele não tá morto, eu sei. Deus deu pra gente a vida é eterna - ninguém é capaz de tirá a vida de ninguém. Nossa alma vive pra sempre nos braços de Nosso Senhor. Essa foi a sua promessa para seus filhos. Por isso eu sei que os médicos estão errados, meu filho vive.

Paul Ricoeur faz vários questionamentos sobre como proceder mediante a morte, como compreender a morte do outro e de que maneira é possível estabelecer um lugar na vida dos vivos para que o morto continue existindo. "Há primeiro o encontro da morte de outro ser querido, de outros desconhecidos. Alguém desapareceu. Uma questão surge e ressurge obstinadamente: ele ainda existe? Onde? Em que outro lugar?" (2012, p. 8). Certamente a memória é um lugar sagrado para preservar a identidade dos mortos que, respondendo a Ricoeur, vivem por inteiro nas lembranças dos vivos. Pelo que percebemos em nossa investigação, na memória a maternidade também pode ser perpetuada uma vez que, sem essa dimensão, a identidade da mulher como ser humano fica sem conteúdo, o que seria insuportável para essa mãe nesse momento específico de sua vida. 


\section{CONCLUSÃO}

Ao finalizarmos a análise dos depoimentos das seis mulheres-mães que colaboraram com esta investigação, percebemos que a religião, ao longo da história, desempenhou importante papel na construção e manutenção de uma concepção idealizada de maternidade, na qual a mulher, enquanto sujeito social, é suprimida e sua função de mãe é sacralizada. $O$ item sobre a religião como um elemento estruturante das concepções de gênero e de maternidade aponta que a religião, enquanto elemento estruturante das concepções de gênero e de maternidade, contribui com a construção, consolidação e manutenção de uma ideologia que passou a exaltar o papel natural da mulher como mãe, atribuindo-lhe todos os deveres e obrigações na criação do(a)s filho(a) s e limitando a função social feminina à realização da maternidade. $\mathrm{O}$ segundo tópico, que trata das concepções de maternidade, entrecruzadas com as crenças e práticas religiosas das mulheres entrevistadas, destaca o fato de que grande parte das mulheres-mães criam seus filhos em situações muito precárias do ponto de vista econômico, social e cultural, gerando nelas um sentimento de paradoxo: por um lado, desejam responder à expectativa gerada em torno de uma maternidade idealizada, por outro lado, percebem a impossibilidade de que isso ocorra e veem seus filhos crescendo e desenvolvendo um perfil não desejado por elas. A situação de vulnerabilidade humana e social vivenciada pelas mulheres que se veem às voltas com a realidade de ter que entrar em contato e reconhecer seu(sua) filho(a), vítima de morte violenta, coloca a elas a necessidade de encontrar um significado convincente para aquilo que estão experienciando. É então que elas, muitas vezes, recorrem aos mesmos significados religiosos conferidos tradicionalmente à maternidade, buscando neles um refúgio para suas dores. Ora elas os reforçam, ora os ressignificam mostrando, assim, a ambiguidade do papel da religião nas concepções de gênero e de maternidade.

\section{REFERÊNCIAS BIBLIOGRÁFICAS}

BADINTER, Elisabeth. Um amor conquistado: o mito do amor materno. Rio de Janeiro: Nova Fronteira, 1985.

BAUMAN, Zygmunt. A Arte da Vida. Rio de Janeiro: Jorge Zahar Editor, 2008. 
BUTLER, Judith. Problemas de gênero: Rio de Janeiro: Civilização Brasileira, 2003. BOURDIEU, Pierre. A economia das trocas simbólicas. São Paulo: Perspectivas,1998. CHODOROW, Nancy. Psicanálise da Maternidade. Rio de Janeiro: Rosa dos Tempos, 1980. DELUMEAU, Jean. O pecado e o medo: a culpabilização no ocidente (século 13-18). Vol. I e II. Bauru: Educ, 2003.

DERRIDA, Jacques. Aporias: morrer - esperar-se nos "limites da verdade". São Paulo: Horizonte, 2018.

FERRAND, Michèle. A questão dos direitos reprodutivos na França. Estudos Feministas, v. 2, n. especial, 1994, pp.79-85.

FERRAND, Michèle. Relações sociais de sexo, maternidade e paternidade. Trad. Soraya Tahran, 1987, mimeografado.

FOUQUET, Catherine; KNIBIEHLER, Yvonne. Histoire des mères du Moyen Âge à nos jours. Paris: Montalba, 1977.

GEERTZ, Clifford. A interpretação das culturas. Rio de Janeiro: LTC, 2008.

GIDDENS, Anthony. A transformação da intimidade: sexualidade, amor e erotismo nas sociedades modernas. São Paulo: UNESP, 1993.

HEIDEGGER, Martin. Ser e tempo. Petrópolis: Vozes, 2012.

IPEA. Atlas da Violência de 2018. Disponível em: < https://www.ipea.gov.br/portal/index. php?option=com_content\&view=article\&id=33410\&ltemid=432 >. Acesso em: 16/11/2021.

LIGA DA JUVENTUDE ISLÂMICA DO BRASIL. Entrevista com o Chaikh Mohamad AI Bukai. In: Islamismo. Disponível em: < https://vidaconcebida.com.br/islamismo.html >. Acesso em: 23/04/2021.

MATTAR, Laura Davis; DINIZ, Carmen Simone Grilo. Hierarquias reprodutivas: maternidade e desigualdades no exercício de direitos humanos pelas mulheres. Interface, $v$. 16, n. 40, 2012, pp. 107-120.

MARTINS, Joel; BICUDO, Maria Aparecida Viggiani. A Pesquisa Qualitativa em Psicologia: Fundamentos e Recursos Básicos. São Paulo: Morais, 2003.

MINAYO, Maria Cecília de Souza. O desafio do conhecimento: pesquisa qualitativa em saúde. São Paulo: Hucitec, 2014.

MOSCOVICI, Serge. A Representação Social da Psicanálise. Rio de Janeiro: Zahar Editores, 1978.

MOLTMANN, Jürgen. A fonte da vida: o Espírito Santo e a teologia da vida. São Paulo: Loyola, 2002.

NETTO, José de Paiva. Laços espirituais entre mãe e filho. Depoimento do presidente-pregador da Religião de Deus, do Cristo e do Espírito Santo. Publicado pela Redação do site da Igreja, dia 08/05/2018. Disponível em: < https://www.religiaodedeus.org/pt/ religiao-no-dia-dia/lacos-espirituais-entre-mae-e-filho >. Acesso em: 23/04/2021. 
NOGUEIRA, Adriana Tanese. A maternidade real: gestação, parto e convivência sem romantização. Psicologia dialética: revisitando a psicologia e a vida real, Disponível em: < http://www.psicologiadialetica.com/2017/07/a-maternidade-real-gestacao-parto-e. html?view=magazine $>$. Acesso em: 07/05/2021.

PAPA FRANCISCO. Ensinamentos do Papa Francisco sobre a maternidade. Publicado no site da Canção Nova, dia 09/05/2019. Disponível em: < https://blog.cancaonova.com/ vocacional/5-ensinamentos-papa-francisco-sobre-maternidade/ >. Acesso em: 23/04/2021.

RICOEUR, Paul. Vivo até a morte: seguido de fragmentos. São Paulo: Martins Fontes, 2012.

RUBIN, Gayle. O tráfego de mulheres: notas sobre a "economia política" do sexo. Recife: S.O.S. Corpo, 1993.

SCOTT, Joan. Gênero: uma categoria útil para análise histórica. Recife: S.O.S. Corpo, 1991. SIMMEL, Georg. Religião: ensaios volume 1/2. São Paulo: Olha D’Água, 2010.

TANQUEREY, Adolphe. Compêndio de Teologia Ascética e Mística. São Pulo: Ecclesiae, 2018.

WAISELFISZ, Julio Jacobo. Mapa da violência 2018: Adolescentes de 16 e 17 anos do Brasil. Brasília: Flacso Brasil, 2018.

Submetido em: 7-5-2021

Aceito em: 16-11-2021 